\title{
Potential impacts of the 2017 American College of Cardiology/American Heart Association high blood pressure guideline on Chinese adults and how to address them
}

Yundi Jiao', Zhaoging Sun ${ }^{1}$, Yanxia Xie ${ }^{2}$, Jia Zheng ${ }^{2}$, Zhao Li ${ }^{3}$, Xiaofan Guo ${ }^{3}$, Yue Dai ${ }^{2}$, Liqiang Zheng ${ }^{2^{*}}$ and Yingxian $\operatorname{Sun}^{1 *}$

\begin{abstract}
Background: The current analysis was performed to estimate the percentage and number of Chinese adults with hypertension and the percentage and number of Chinese adults recommended to receive pharmacological antihypertensive treatment according to the 2017 American College of Cardiology/American Heart Association (ACC/AHA) guideline compared with the same parameters according to the 2010 Chinese guideline.

Methods: We used 2011 data from the China Health and Nutrition Survey (CHNS). A total of 12,499 Chinese adults aged $\geq 18$ years with complete blood pressure (BP) values were selected for the present analysis.

Results: The crude prevalence rates $(95 \% \mathrm{Cl})$ of hypertension according to the definitions from the $2017 \mathrm{ACC} / \mathrm{AHA}$ guideline and the 2010 Chinese guideline were 58.0\% (57.2 to 58.9\%) and 25.4\% (24.7 to 26.2\%), respectively. Moreover, the percentage of the participants recommended to take antihypertensive medications were 31.5 and 28.8\%, respectively. Among adults who took antihypertensive medications, $88.8 \%$ had above-goal BP levels compared to 53.3\%. Overall, 613.3 million Chinese adults (aged $\geq 18$ years) met the criteria for hypertension according to the 2017 ACC/AHA guideline, and 267.7 million met the criteria according to 2010 Chinese guideline. An additional 28.4 million (2.7\%) Chinese adults were recommended to take antihypertensive medication.

\footnotetext{
*Correspondence: liqiangzheng@126.com; sunyingxian12@126.com

${ }^{2}$ Department of Clinical Epidemiology, Department of Library, Shengjing

Hospital of China Medical University, 36 Sanhao Street, Heping District,

Shenyang 110004, People's Republic of China

'Department of Cardiology, Shengjing Hospital of China Medical University,

36 Sanhao Street, Heping District, Shenyang 110004, People's Republic of

China

Full list of author information is available at the end of the article
}

(C) The Author(s). 2020 Open Access This article is licensed under a Creative Commons Attribution 4.0 International License, which permits use, sharing, adaptation, distribution and reproduction in any medium or format, as long as you give appropriate credit to the original author(s) and the source, provide a link to the Creative Commons licence, and indicate if changes were made. The images or other third party material in this article are included in the article's Creative Commons licence, unless indicated otherwise in a credit line to the material. If material is not included in the article's Creative Commons licence and your intended use is not permitted by statutory regulation or exceeds the permitted use, you will need to obtain permission directly from the copyright holder. To view a copy of this licence, visit http://creativecommons.org/licenses/by/4.0/ The Creative Commons Public Domain Dedication waiver (http://creativecommons.org/publicdomain/zero/1.0/) applies to the data made available in this article, unless otherwise stated in a credit line to the data. 
(Continued from previous page)

Conclusions: The present analysis revealed that the 2017 ACC/AHA hypertension guideline will result in a substantial increase in the percentage and number of Chinese adults defined as having hypertension and a small increase in the percentage of adults who are recommended to take antihypertensive medications compared to the same parameters based on the 2010 Chinese guideline. More intensive management and antihypertensive medications use are suggested to improve the control rate of hypertension among Chinese adults.

Keywords: Hypertension, Guideline, Prevalence, Antihypertensive medications

\section{Backgroud}

On November 13, 2017, the American College of Cardiology/American Heart Association (ACC/AHA) Guideline for the Prevention, Detection, Evaluation and Management of High Blood Pressure in Adults was published [1]. The guideline substantially updated the Seventh Report of the Joint National Committee on the Prevention, Detection, Evaluation and Treatment of High Blood Pressure (JNC7) in 2003 [2] and provided more information on the prevention and treatment of hypertension. The guideline will help us provide more intensive care for high blood pressure and reduce the incidence of cardiovascular diseases such as stroke, heart attack, and heart failure. Paul Muntner et al. [3] indicated that the 2017 ACC/AHA guideline will increase the prevalence of hypertension, compared to that based on the JNC7 guideline, from 31.9 to $45.6 \%$ based on the representative sample of the 2011-2014 National Health and Nutrition Examination Survey (NHANES). However, the percentage of US adults who were recommended to take antihypertensive medication increased slightly by $1.9 \%$ (from 34.3 to $36.2 \%$ ). In addition, among US adults taking antihypertensive medication, 53.4 and $39.0 \%$ had blood pressure above the treatment goal according to the 2017 ACC/AHA and JNC7 guideline, respectively. A substantial proportion of US adults taking antihypertensive medication are recommended to undergo more intensive blood pressure lowering based on the 2017 ACC/AHA guideline.

China is experiencing a high prevalence and a low rate of treatment and control of hypertension $[4,5]$. In recent decades, the prevalence and incidence of hypertension have increased markedly in China, especially in rural areas $[4,6,7]$. Recently, a study that included 1.7 million adults (aged 35 to 75 years) revealed that the prevalence of hypertension was $44.7 \%$, whereas the rates of hypertensive medication used and BP goal achievement in hypertensive patients were 30.1 and $7.2 \%$ [5], respectively. Compared to the JNC7 guideline and the Chinese guideline for high blood pressure, the 2017 ACC/AHA guideline recommends using lower systolic blood pressure (SBP) and diastolic blood pressure (DBP) levels to define hypertension $(130 / 80 \mathrm{mmHg})$. The new definition has substantially increased the number of hypertensive patients in the US. The potential impact of the 2017 ACC/AHA guideline in China remains to be elucidated.

The current analysis used data from the China Health and Nutrition Survey (CHNS) in 2011 to estimate the percentage and number of Chinese adults with hypertension and those recommended to undergo pharmacological antihypertensive treatment according to the 2017 ACC/AHA guideline compared with the same parameters based on the 2010 Chinese guideline for the Management of Hypertension. In addition, we estimated the percentage and number of Chinese adults taking antihypertensive medication with blood pressure above the goal using the targets from each guideline.

\section{Methods}

\section{Study sample}

The CHNS is a follow-up survey regarding nutrition and food safety conducted by the Chinese Center for Disease Control and Prevention in collaboration with the Population Center of the University of North Carolina in the United States. The CHNS aimed to develop a longitudinal and multipurpose survey that could help the group measure health factors of interest, such as sociological, economic and demographic factors, for use by the CAPM (formerly the Chinese Academy of Preventive Medicine) and scholars [8]. Since 1989, the CHNS has been conducted nine times (1989, 1991, 1993, 1997, 2000, 2004, 2006, 2009, and 2011) and has covered nine provinces (Liaoning, Heilongjiang, Jiangsu, Shandong, Henan, Hubei, Hunan, Guangxi and Guizhou), including urban and rural areas categorized by income (low, middle, and high). CHNS used a multistage stratified cluster random sampling method, and a weighted sampling scheme was used to randomly select four counties in each province [9]. We used the 2011 health data of residents for this analysis. For the present analysis, the 2011 data were restricted to those of adult participants aged $\geq 18$ years $(n=13,052)$. Participants were excluded if the three blood pressure (SBP or DBP) measurements were not available in the survey $(n=$ 553), leaving 12,499 Chinese adults aged $\geq 18$ years with complete blood pressure values for the present analysis. 


\section{Data collection}

In the CHNS, standard questionnaires were used to collect basic information and related biochemical indicators were measured in a national central lab in Beijing (medical laboratory accreditation certificate ISO 15189: 2007) with strict quality control [10]. Blood pressure was measured by trained examiners using a mercury sphygmomanometer with a suitable cuff size according to a standard protocol [5]. Three measurements were taken $10 \mathrm{~min}$ after rest, and the average of the three measurements was used for the analysis [11]. In addition, the questionnaire asked whether the participant had a history of use of antihypertensive drugs.

Cardiovascular disease (CVD) history was defined by a self-reported previous diagnosis of myocardial infarction or stroke. The definitions of hypertension, recommended antihypertensive drug standards and recommended blood

Table 1 Blood pressure levels used to define hypertension, recommend antihypertensive medication, and treatment goal according to the 2017 ACC/AHA Guideline and the 2010 Chinese Guideline

\begin{tabular}{|c|c|c|}
\hline & \multicolumn{2}{|c|}{ Guideline - Definition of hypertension } \\
\hline & 2017 ACC/AHA & 2010 Chinese \\
\hline $\mathrm{SBP}, \mathrm{mmHg}$ & $\geq 130$ & $\geq 140$ \\
\hline \multirow[t]{3}{*}{$\mathrm{DBP}, \mathrm{mmHg}$} & $\geq 80$ & $\geq 90$ \\
\hline & \multicolumn{2}{|c|}{$\begin{array}{l}\text { Guideline - Recommended } \\
\text { antihypertensive medication }\end{array}$} \\
\hline & 2017 ACC/AHA & 2010 Chinese \\
\hline \multicolumn{3}{|l|}{$\mathrm{SBP}, \mathrm{mmHg}$} \\
\hline General population & $\geq 140$ & $\geq 140$ \\
\hline Aged $\geq 65$ years & $\geq 130$ & $\geq 140$ \\
\hline Diabetes & $\geq 130$ & $\geq 130$ \\
\hline CHD or stroke & $\geq 130$ & $\geq 140$ \\
\hline \multicolumn{3}{|l|}{$\mathrm{DBP}, \mathrm{mmHg}$} \\
\hline General population & $\geq 90$ & $\geq 90$ \\
\hline Aged $\geq 65$ years & $\geq 80$ & $\geq 90$ \\
\hline Diabetes & $\geq 80$ & $\geq 80$ \\
\hline \multirow[t]{3}{*}{ CHD or stroke } & $\geq 80$ & $\geq 90$ \\
\hline & \multicolumn{2}{|c|}{$\begin{array}{l}\text { Treatment goal among those taking } \\
\text { antihypertensive medication }\end{array}$} \\
\hline & 2017 ACC/AHA & 2010 Chinese \\
\hline \multicolumn{3}{|l|}{$\mathrm{SBP}, \mathrm{mmHg}$} \\
\hline General population & $<130$ & $<140$ \\
\hline Aged $\geq 65$ years & $<130$ & $<150$ \\
\hline Diabetes or CHD or stroke & $<130$ & $<130$ \\
\hline \multicolumn{3}{|l|}{$\mathrm{DBP}, \mathrm{mmHg}$} \\
\hline General population & $<80$ & $<90$ \\
\hline Diabetes or CHD or stroke & $<80$ & $<80$ \\
\hline
\end{tabular}

$S B P$ systolic blood pressure; $D B P$ diastolic blood pressure; $C H D$ coronary heart disease pressure targets for adults taking antihypertensive drugs referred to the 2017 ACC/AHA guideline and the 2010 Chinese guideline for the management of hypertension are presented in Table 1.

\section{Statistical analysis}

Continuous variables were presented as mean \pm standard deviation (SD) or median [interquartile range, IQR], while categorical variables were expressed as counts and percentages (\%). We calculated the distribution of the Chinese adults across five groups, including four groups that did not take antihypertensive medication (SBP/DBP $<120 /<80,120-129 /<80,130-139 / 80-89$, and $\geq 140 /$ $90 \mathrm{mmHg}$ ) and a group taking antihypertensive drugs. Patient groups were compared by $x^{2}$ tests for categorical variables or one-way analysis of variance for continuous variables. We calculated the percentage and number (95\% CI) of adults with hypertension in China and the percentage and number of people who were recommended to receive antihypertensive therapy based on the 2017 ACC/AHA guideline, the 2010 Chinese guideline, and the differences between the two guidelines (the 2017 ACC/AHA guideline but not the 2010 Chinese guideline). These calculations were performed in the general population and in different subgroups (such as groups with different ages and sexes). Moreover, the above method was used to calculate the Chinese demographic and clinical characteristics of blood pressure above the goal according to the 2017 ACC/AHA guideline and the 2010 Chinese guideline. Data from the sixth national census in 2010 were used to calculate the numbers of individuals with prevalent hypertension, who are recommended to take antihypertensive medications, and who have blood pressure above the goal. All analyses were performed with SPSS statistical software version 13.0 (SPSS Inc., Chicago, IL, USA) and SAS statistical software version 9.2 (SAS Institute Inc., Carey, NC, USA). A $P$ value less than 0.05 was accepted as indicating statistical significance.

\section{Results}

The median age of the present study participants was $51.0 \pm 15.2$ years, and $53.3 \%$ were women. A total of $13.4 \%$ (1663) of Chinese adults were taking antihypertensive medications. A total of 32.0, 9.7, 30.1 and 14.6\% of Chinese adults not taking antihypertensive medications had $\mathrm{SBP} /$ DBP levels of $<120 / 80,120-129 /<80,130-139 / 80-89$, and $\geq 140 / 90 \mathrm{mmHg}$, respectively (Table 2). Table 2 shows the baseline characteristics of the study participants according to different BP subgroups. As expected, Chinese adults with higher blood pressure were older and more likely to be men, current smokers and to have diabetes and a history of stroke and coronary heart disease (all $P<0.001$ ). 
Table 2 Characteristics of Chinese adults (aged $\geq 18$ years) by blood pressure levels and antihypertensive medication use based on the 2011 China Health and Nutrition Survey $(n=12,499)$

\begin{tabular}{|c|c|c|c|c|c|c|}
\hline \multirow[t]{2}{*}{ Characteristics } & \multicolumn{4}{|c|}{$\begin{array}{l}\text { SBP/DBP categories in mmHg among Chinese adults not taking } \\
\text { antihypertensive medication }\end{array}$} & \multirow[t]{2}{*}{$\begin{array}{l}\text { Taking antihypertensive } \\
\text { medication }(n=1663)\end{array}$} & \multirow[t]{2}{*}{$P$-Value } \\
\hline & $\begin{array}{l}<120 / 80 \\
(n=4027)\end{array}$ & $\begin{array}{l}120-129 /<80 \\
(n=1218)\end{array}$ & $\begin{array}{l}130-139 / 80-89 \\
(n=3768)\end{array}$ & $\begin{array}{l}\geq 140 / 90 \\
(n=1823)\end{array}$ & & \\
\hline Percentage of Chinese population & 32.2 & 9.7 & 30.1 & 14.6 & 13.4 & $<0.001$ \\
\hline \multicolumn{7}{|l|}{ Population characteristics ${ }^{a}$} \\
\hline Age, year & $43.0(33.0-55.0)$ & $51.0(39.0-61.0)$ & $50.0(41.0-59.0)$ & $57.0(48.0-66.0)$ & $62.0(56.0-71.0)$ & $<0.001$ \\
\hline Women, \% & 63.9 & 48.9 & 46.8 & 44.2 & 53.3 & $<0.001$ \\
\hline Current smoking, \% & 22.9 & 34.8 & 34.3 & 38.3 & 30.5 & $<0.001$ \\
\hline Diabetes, \% & 1.4 & 2.9 & 3.0 & 4.4 & 4.1 & $<0.001$ \\
\hline $\mathrm{SBP}, \mathrm{mmHg}$ & $108.1 \pm 8.1$ & $123.2 \pm 3.1$ & $124.5 \pm 8.3$ & $144.6 \pm 15.3$ & $124.5 \pm 17.7$ & $<0.001$ \\
\hline $\mathrm{DBP}, \mathrm{mmHg}$ & $70.0 \pm 6.2$ & $74.0 \pm 4.8$ & $81.8 \pm 4.2$ & $90.9 \pm 10.0$ & $79.3 \pm 10.7$ & $<0.001$ \\
\hline The history of coronary heart disease, $\%$ & 0.4 & 0.4 & 0.5 & 0.7 & 0.9 & $<0.001$ \\
\hline The history of Stroke, \% & 0.4 & 0.9 & 0.6 & 1.4 & 1.6 & $<0.001$ \\
\hline The history of $\mathrm{CVD}^{c}, \%$ & 0.7 & 1.2 & 1.0 & 2.0 & 2.4 & $<0.001$ \\
\hline
\end{tabular}

${ }^{a}$ Population characteristics in the table are percentage or mean (standard deviation)

${ }^{b} P$-values were calculated by one-way ANOVA or chi-square test to compare differences within different blood pressure categories

'Defined by a self-reported history of stroke or coronary heart disease

2017 ACC/AHA Guideline - 2017 American College of Cardiology / American Heart Association Guideline for the Prevention, Detection, Evaluation and Management of High Blood Pressure in Adults

SBP systolic blood pressure; DBP diastolic blood pressure; CVD cardiovascular disease

The prevalence rates $(95 \% \mathrm{CI})$ of hypertension according to the definitions from the 2017 ACC/AHA guideline and the 2010 Chinese guideline were 58.0\% (57.2 to $58.9 \%$ ) and $25.4 \%$ (24.7 to $26.2 \%$ ), respectively (Table 3). The prevalence of hypertension was higher when based on the 2017 ACC/AHA guideline compared to that based on the 2010 Chinese guideline within all age, sex, and CVD history subgroups. In addition, the difference in prevalence defined by the 2017 ACC/AHA guideline but not the 2010 Chinese guideline was significant among the different subgroups $(P<0.05)($ Table 3$)$.

Table 3 Prevalence (95\% CI) of hypertension according to the definition from 2017 ACC/AHA Guideline and the 2010 China Hypertension Guideline based on the 2011 China Health and Nutrition Survey $(n=12,499)$

\begin{tabular}{llll}
\hline & 2017 ACC/AHA Guideline & 2010 Chinese Hypertension Guideline & $\begin{array}{l}\text { Difference (2017 ACC/AHA but not } \\
\text { 2010 Chinese Hypertension Guideline) }\end{array}$ \\
\hline $\begin{array}{l}\text { Overall } \\
\text { Age, years }\end{array}$ & $58.0(57.2,58.9)$ & $25.4(24.7,26.2)$ & $32.6(31.8,33.4)$ \\
$18-34$ & $30.3(28.3,32.4)$ & $3.4(2.6,4.2)$ & $26.9(25.0,28.9)$ \\
$35-44$ & $47.2(45.2,49.3)$ & $10.4(9.2,11.7)$ & $36.8(34.8,38.8)$ \\
$45-54$ & $61.1(59.3,62.9)$ & $22.9(21.3,24.4)$ & $38.2(36.5,40.0)$ \\
$55-64$ & $68.3(66.6,69.9)$ & $35.5(33.8,37.2)$ & $32.8(31.1,34.4)$ \\
$65-74$ & $72.9(70.7,75.1)$ & $46.6(44.1,49.0)$ & $26.3(24.2,28.5)$ \\
$\geq 75$ & $78.0(75.1,80.8)$ & $51.4(47.9,54.8)$ & $26.6(23.6,29.7)^{\mathrm{b}}$ \\
Sex & & & $37.2(35.6,38.4)$ \\
Men & $64.4(63.2,65.6)$ & $27.2(26.1,28.4)$ & $28.6(22.5,29.7)^{\mathrm{b}}$ \\
Women & $52.5(51.3,53.7)$ & $23.8(22.8,24.9)$ & $13.9(10.0,17.8)$ \\
The history of CVD ${ }^{\mathrm{a}}$ & & & $33.1(32.2,33.9)^{\mathrm{b}}$ \\
Yes & $85.1(81.1,89.2)$ & $24.3(23.5,25.0)$ & \\
No & $57.4(56.5,58.2)$ & & \\
\hline
\end{tabular}

${ }^{a}$ Defined by a self-reported history of stroke or coronary heart disease

${ }^{\mathrm{b}}$ Chi-square test for Comparison among different subgroups, $P<0.05$

2017 ACC/AHA Guideline - 2017 American College of Cardiology / American Heart Association Guideline for the Prevention, Detection, Evaluation and Management of High Blood Pressure in Adults 
The percentage of individuals recommended to take antihypertensive medications among Chinese adults was 31.5 and $28.8 \%$ according to the $2017 \mathrm{ACC} /$ AHA guideline and 2010 Chinese guideline, respectively. An increase in the percentage of the population recommended to take antihypertensive medication based on the 2017 ACC/AHA guideline compared to that based on the 2010 Chinese guideline was present in all subgroups. The subgroups of individuals with an older age and a history of CVD had a relatively higher increase relative to adults with a young age and without CVD history (Table 4). Among Chinese adults with SBP/DBP of 130-139/80-89 $\mathrm{mmHg}, 12.0 \%$ were recommended to take antihypertensive medication according to the 2017 ACC/AHA guideline because they had diabetes, CVD history or SBP of $130-139 \mathrm{mmHg}$ and were $\geq 65$ years of age.

In 2011, 613.3 million Chinese adults ( $\geq 18$ years) met the criteria for hypertension according to the $2017 \mathrm{ACC} /$ AHA guideline compared with 267.7 million Chinese adults according to the 2010 Chinese guideline (Table 5). Using the recommendation from the 2017 ACC/AHA guideline, 332.0 million Chinese adults not taking antihypertensive medications met the criteria for treatment with antihypertensive medication in addition to nonpharmacological interventions, whereas 303.6 million met the criteria for treatment with nonpharmacological therapy. An additional 28.4 million Chinese adults were recommended to take antihypertensive medication according to the 2017
ACC/AHA guideline compared with the 2010 Chinese guideline.

Among these Chinese adults taking antihypertensive medications, $88.8 \%$ had above-goal $\mathrm{BP}$ according to the 2017 ACC/AHA guideline compared to 53.3\% with abovegoal BP according to the 2010 Chinese guideline (Table 6). Additionally, the prevalence of blood pressure above the goal, defined by the 2017 ACC/AHA guideline compared to that defined by the 2010 Chinese guideline, was more than $25 \%$ higher in each subgroup investigated except for those aged $45-54$ years.

\section{Discussion}

The present analysis indicates the potential impacts of the 2017 ACC/AHA guideline on the definition of hypertension, recommendation for antihypertensive medication in addition to nonpharmacological interventions and blood pressure goals in individuals receiving antihypertensive drug treatment among Chinese adults (Figs. 1 and 2). The present analysis revealed that the 2017 ACC/AHA hypertension guideline will result in a substantial increase in the percentage and number of Chinese adults defined as having hypertension. However, the percentage of adults who are recommended to take antihypertensive medications will only increase minimally (2.7\%) according to the 2017 ACC/AHA guideline compared to that based on the 2010 Chinese guideline. In addition, $35.5 \%$ of Chinese adults taking antihypertensive medication had a blood pressure

Table 4 Percentage $(95 \% \mathrm{Cl})$ of Chinese adults meeting the definition for recommended antihypertensive medication according to the 2017 ACC/AHA Guideline and the 2010 China Hypertension Guideline based on the 2011 China Health and Nutrition Survey $(n=12,499)$

\begin{tabular}{|c|c|c|c|}
\hline & \multicolumn{2}{|c|}{ Recommended antihypertensive medication } & \multirow{2}{*}{$\begin{array}{l}\text { Difference (2017 ACC/ } \\
\text { AHA but not } 2010 \text { Chinese } \\
\text { Hypertension Guideline) }\end{array}$} \\
\hline & 2017 ACC/AHA Guideline & 2010 Chinese Hypertension Guideline & \\
\hline Overall & $31.5(30.7,32.3)$ & 28.8(28.0,29.6) & $2.7(2.4,3.0)$ \\
\hline \multicolumn{4}{|l|}{ Age, years } \\
\hline $18-34$ & $5.0(4.0,5.9)$ & $5.0(4.0,5.9)$ & $0.0(0.0,0.0)$ \\
\hline $35-44$ & $12.4(11.1,13.8)$ & $12.3(11.0,13.7)$ & $0.1(0.03,0.2)$ \\
\hline $45-54$ & $27.2(25.6,28.9)$ & $27.2(25.6,28.8)$ & $0.0(0.0,0.0)$ \\
\hline $55-64$ & $40.1(38.4,41.9)$ & $39.6(37.9,41.4)$ & $0.5(0.2,0.7)$ \\
\hline $65-74$ & $64.3(62.0,66.7)$ & $50.9(48.5,58.4)$ & $13.4(11.7,15.1)$ \\
\hline$\geq 75$ & $68.8(65.6,72.0)$ & $52.2(51.8,58.6)$ & $13.6(11.2,16.0)^{b}$ \\
\hline \multicolumn{4}{|l|}{ Sex } \\
\hline Men & $33.9(32.7,35.2)$ & $31.1(29.9,32.3)$ & $2.8(2.4,3.3)$ \\
\hline Women & $29.4(28.3,30.5)$ & $26.8(25.7,27.8)$ & $2.6(2.2,3.0)$ \\
\hline \multicolumn{4}{|c|}{ The history of CVD a } \\
\hline Yes & $85.1(81.1,89.2)$ & $73.9(69.0,78.9)$ & $11.2(7.7,14.8)$ \\
\hline No & $30.2(29.4,31.0)$ & $27.7(26.9,28.5)$ & $2.5(2.2,2.8)^{b}$ \\
\hline
\end{tabular}

${ }^{a}$ Defined by a self-reported history of stroke or coronary heart disease

${ }^{\mathrm{b}} \mathrm{Chi}$-square test for Comparison among different subgroups, $P<0.05$

2017 ACC/AHA Guideline - 2017 American College of Cardiology / American Heart Association Guideline for the Prevention, Detection, Evaluation and Management of High Blood Pressure in Adults 
Table 5 Number of China adults, in million, meeting the definition for hypertension and the definition for treatment with antihypertensive medication according to the 2017 ACC/AHA Guideline and the 2010 China Hypertension Guideline based on the 2011 China Health and Nutrition Survey

\begin{tabular}{|c|c|c|c|c|c|c|}
\hline & \multicolumn{2}{|c|}{2017 ACC/AHA Guideline } & \multicolumn{2}{|c|}{2010 Chinese Hypertension Guideline } & \multicolumn{2}{|c|}{ Difference (2017ACC/AHA vs 2010 Chinese) } \\
\hline & Hypertension & $\begin{array}{l}\text { Recommended } \\
\text { antihypertensive } \\
\text { medication }\end{array}$ & Hypertension & $\begin{array}{l}\text { Recommended } \\
\text { antihypertensive } \\
\text { medication }\end{array}$ & Hypertension & $\begin{array}{l}\text { Recommended } \\
\text { antihypertensive } \\
\text { medication }\end{array}$ \\
\hline Overall & $611.3(602.9,620.8)$ & $332.0(323.6,340.4)$ & $267.7(260.3,276.1)$ & $303.6(295.1,312.0)$ & $343.6(335.2,352.0)$ & $28.4(25.3,31.6)$ \\
\hline \multicolumn{7}{|l|}{ Age, years } \\
\hline $18-34$ & $50.1(48.9,55.0)$ & $8.3(6.6,10.0)$ & $5.6(5.4,8.0)$ & $8.3(6.1,9.1)$ & $44.5(41.23,48.1)$ & $0.0(0.0,0.0)$ \\
\hline $35-44$ & $91.1(85.6,97.8)$ & $24.0(19.9,26.6)$ & $20.1(18.7,21.4)$ & $23.9(21.3,27.3)$ & $71.1(65.3,75.6)$ & $0.2(0.06,0.40)$ \\
\hline $45-54$ & $145.5(140.6,152.8)$ & $64.7(59.8,69.7)$ & $54.3(50.9,58.9)$ & $64.7(60.7,69.8)$ & $91.2(85.9,96.2)$ & $0.1(0.08,0.25)$ \\
\hline $55-64$ & $173.6(165.0,177.3)$ & 102.3(96.3, 106.2) & $90.5(85.7,93.7)$ & $101.1(97.2,106.3)$ & $83.1(79.0,89.3)$ & $1.2(0.6,2.0)$ \\
\hline $65-74$ & $97.2(91.7,103.9)$ & $85.9(83.0,89.6)$ & $62.1(58.9,66.9)$ & $68.0(63.8,72.9)$ & $35.1(30.9,37.8)$ & $17.8(16.3,19.2)$ \\
\hline$\geq 75$ & $53.2(48.9,55.0)$ & $46.8(43.2,49.8)$ & $35.1(32.1,37.5)$ & $37.6(33.4,39.5)$ & 18.1(17.2, 20.6) & $9.2(7.8,10.6)$ \\
\hline \multicolumn{7}{|l|}{ Sex } \\
\hline Men & $316.7(311.8,324.0)$ & $167.0(162.7,172.6)$ & $133.9(128.5,139.2)$ & 153.0(148.8, 157.8) & $182.8(178.7,189.0)$ & $13.9(12.4,15.4)$ \\
\hline Women & $294.6(287.3,299.5)$ & 165.0(159.4, 169.3) & $133.9(128.5,139.2)$ & 150.6(145.7, 154.8) & $160.7(154.6,164.9)$ & $14.5(13.1,16.1)$ \\
\hline \multicolumn{7}{|c|}{ The history of $C V D^{a}$} \\
\hline Yes & $22.0(18.3,24.5)$ & $21.9(19.9,23.24)$ & $18.2(16.1,21.4)$ & $18.8(18.2,21.3)$ & $3.8(2.4,4.5)$ & $2.7(1.9,3.8)$ \\
\hline No & $589.3(586.8,593.0)$ & $310.1(308.8,312.1)$ & $249.5(246.3,251.6)$ & $284.7(282.3,288.4)$ & $339.8(338.8,340.8)$ & $25.5(24.7,26.6)$ \\
\hline
\end{tabular}

${ }^{\mathrm{a} D e f i n e d ~ b y ~ a ~ s e l f-r e p o r t e d ~ h i s t o r y ~ o f ~ s t r o k e ~ o r ~ c o r o n a r y ~ h e a r t ~ d i s e a s e ~}$

2017 ACC/AHA Guideline - 2017 American College of Cardiology / American Heart Association Guideline for the Prevention, Detection, Evaluation and Management of High Blood Pressure in Adults

Table 6 Percentage $(95 \% \mathrm{Cl})$ of Chinese adults taking antihypertensive medication with blood pressure above goal according to the 2017 ACC/AHA Guideline and the 2010 China Hypertension Guideline based on the 2011 China Health and Nutrition Survey

\begin{tabular}{|c|c|c|c|}
\hline & \multicolumn{2}{|c|}{ Blood pressure above goal according to: } & \multirow{2}{*}{$\begin{array}{l}\text { Difference (2017 ACC/AHA } \\
\text { but not } 2010 \text { Chinese } \\
\text { Hypertension Guideline) }\end{array}$} \\
\hline & 2017 ACC/AHA Guideline & 2010 Chinese Hypertension Guideline & \\
\hline Overall & $88.8(87.2,90.3)$ & $53.3(51.0,55.7)$ & $35.5(33.1,37.7)$ \\
\hline \multicolumn{4}{|l|}{ Age, years } \\
\hline $18-34^{c}$ & - & - & - \\
\hline $35-44$ & $96.9(92.6,100.0)$ & $71.9(60.9,82.9)$ & $25.0(14.4,35.6)$ \\
\hline $45-54$ & $90.1(86.7,93.5)$ & $67.3(62.0,72.6)$ & $22.8(18.1,27.5)$ \\
\hline $55-64$ & $87.8(85.1,90.4)$ & $62.1(58.2,66.0)$ & $25.6(22.1,29.2)$ \\
\hline $65-74$ & $88.6(85.7,91.6)$ & $36.1(31.6,40.6)$ & $52.5(47.8,57.2)$ \\
\hline$\geq 75$ & $87.5(83.6,91.5)$ & $41.5(35.6,47.4)$ & $46.0(40.0,52.0)^{b}$ \\
\hline \multicolumn{4}{|l|}{ Sex } \\
\hline Men & $89.6(87.3,91.8)$ & $53.2(49.6,56.8)$ & $36.4(32.9,39.8)$ \\
\hline Women & $88.1(86.0,90.2)$ & $53.5(50.2,56.7)$ & $34.7(31.6,37.7)$ \\
\hline \multicolumn{4}{|c|}{ The history of $C V D^{a}$} \\
\hline Yes & $88.7(84.2,93.9)$ & $48.4(41.2,55.6)$ & $40.3(33.3,47.4)$ \\
\hline No & $88.8(87.2,90.4)$ & $54.0(51.4,56.5)$ & $34.8(32.4,37.2)$ \\
\hline
\end{tabular}

${ }^{a}$ Defined by a self-reported history of stroke or coronary heart disease

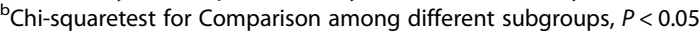

'Small sample size $(n=2)$ is not adapted to calculate the percentage

2017 ACC/AHA Guideline - 2017 American College of Cardiology / American Heart Association Guideline for the Prevention, Detection, Evaluation and Management of High Blood Pressure in Adults 


\section{ACC/AHA And 2010 China Hypertension Guideline}

2017ACC/AHA Not 2010 China Hypertens ion Guideline

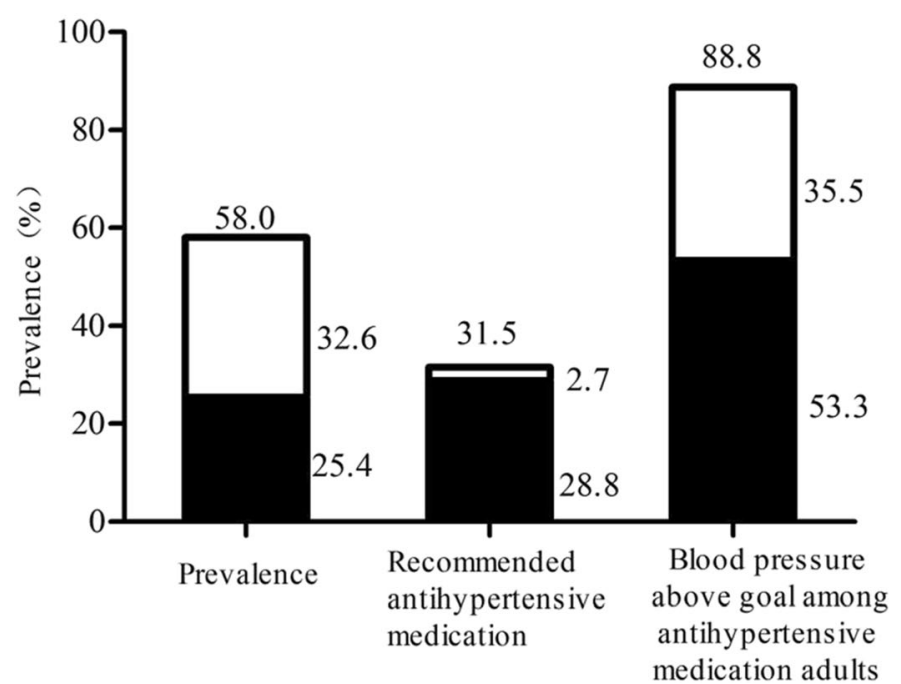

Fig. 1 Prevalence of hypertension, recommendation for pharmacologic antihypertensive treatment, and blood pressure above goal among Chinese adults according to the 2017 ACC/AHA Guideline and the 2010 China Hypertension Guideline

above the goal defined by the 2017 ACC/AHA guideline, whereas they would have met the BP goal according to the 2010 Chinese guideline. More intensive management and antihypertensive medications are suggested to improve the control rate of hypertension among Chinese adults.

There is no doubt that the percentage and number of individuals with hypertension will increase substantially with the change in definition of hypertension according to the 2017 ACC/AHA guideline [1]. The prevalence of hypertension among US adults will have a relative $40 \%$ increase (from 31.9 to $45.6 \%$ ) [3]. Our study offers the exact data on the number of Chinese adults met the criteria for hypertension. The prevalence of hypertension among Chinese adults will increase from 25.6 to $55.6 \%$ according to the 2017 ACC/AHA guideline, and the

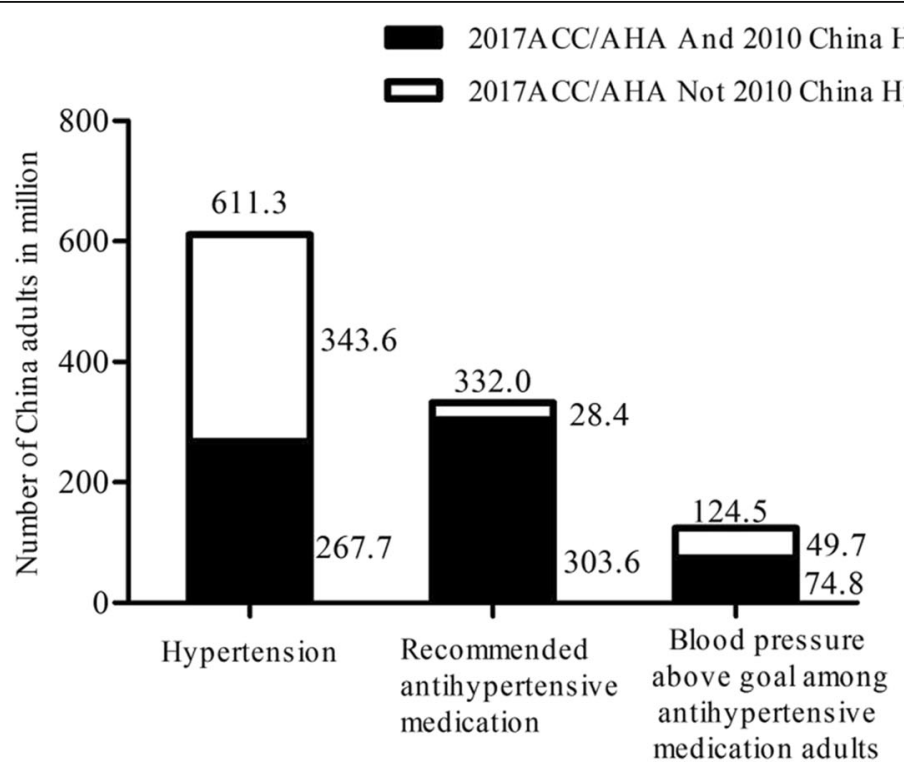

Fig. 2 Numbers of hypertension, recommendation for pharmacologic antihypertensive treatment, and blood pressure above goal among Chinese adults according to the 2017 ACC/AHA Guideline and the 2010 China Hypertension Guideline 
number of individuals with hypertension will also increase steeply from 260 million to 630 million. Therefore, many new prevalent cases will be diagnosed because of the 2017 ACC/AHA guideline. An important question is how to face the challenge. In fact, the percentage of adults with SBP/DBP of 130-139/80-89 $\mathrm{mmHg}$ contributes to the deviation based on the 2017 ACC/AHA guideline. Although several observational studies have demonstrated an association between blood pressure of $130-139 / 80-89 \mathrm{mmHg}$ and the risk of incident CVD [11-16], the 2017 ACC/AHA writing committee still emphasized that there is insufficient evidence to support a recommendation for antihypertensive drug treatment for these individuals to obtain more benefits [3]. However, the findings can provide an opportunity to discuss the value of nonpharmacological therapy in lowering blood pressure, to implement recommended lifestyle changes and to emphasize that blood pressure is a risk factor that can be controlled. Therefore, the aim of the definition is to raise the awareness of these individuals and to encourage the implementation of recommended lifestyle changes; the definition of hypertension is mostly acceptable in China.

In addition, according to the 2017 ACC/AHA guideline, the prevalence of recommended antihypertensive medication among US adults increased by $1.9 \%$ [3], while in the present study, the prevalence of recommended antihypertensive medication increased from 28.8 to $31.5 \%$ according to the 2017 ACC/AHA guideline compared to the 2010 Chinese guideline. The corresponding number of patients receiving antihypertensive medication will increase by 28.4 million. However, we have to consider that we did not consider adults with CVD risk $>10 \%$ because of the shortage of data in this study. Therefore, the percentage and number of individuals recommended to take antihypertensive medications will continue to increase if CVD risk is taken into account. The 2017 ACC/AHA guideline used a combination of CVD risk and blood pressure levels to determine the antihypertensive medication recommendation primarily based on the results of a diverse set of data from post-hoc randomized clinical trials, observational studies and computer simulation analyses $[17,18]$. Large-scale RCTs focusing on the combination of CVD risk and blood pressure levels to determine antihypertensive medication recommendations should be further encouraged. In addition, using the pooled CVD risk equation is not fully popularized in clinical practice and is not feasible for evaluation in the primary health care service setting in China. We also have to consider the overuse of antihypertensive drugs based on the 2017 ACC/AHA guideline concerning recommendation for antihypertensive medication. Finally, we should consider the recommendation carefully and conduct some studies in diverse populations to focus on the necessity of antihypertensive medication use in China.
The control rate of hypertension is relatively low compared to that in Western countries, although it has increased in recent years [4, 5]. According to the 2017 ACC/AHA hypertension guideline, the percentage of individuals with blood pressure above the goal increased from 39.0 to $53.4 \%$ in the US and increased from 53.3 to $88.8 \%$ in China among adults taking antihypertensive medications. In fact, we temporarily suspend the definition of this target and whether it is suitable for Chinese adults. The current situation of high prevalence and low control rate of hypertension in China is unsatisfactory. The benefits of antihypertensive medications for the reduction of CVD events are commonly accepted. Therefore, whether referring to the 2017 ACC/AHA hypertension guideline or the 2010 Chinese hypertension guideline, it is important and necessary to further improve the control rate of hypertension and provide more positive treatment and management for prevalent hypertension. Our results can provide a consult to government and public health agency for seeing the reality of hypertension in China and helping promote public health programs to increase hypertension awareness. Further management strategies for controlling hypertension and reducing the burden of CVD events are essential to promote the Goal of Healthy China 2030.

The present study has strength in that the study population is nationally representative. However, some limitations should also be considered in light of these results. First, blood pressure was measured only once, which may result in the misclassification of blood pressure. Second, we did not have sufficient information from laboratory measurements such as cholesterol, serum glucose, and family history of CVD, to calculate CVD risk, which may have helped us to evaluate the exact impact of the recommended antihypertensive medication on the Chinese population.

\section{Conclusion}

The current analysis demonstrates that the 2017 ACC/ AHA hypertension guideline have a potential impact on the prevalence of hypertension, the prevalence of the recommendation for antihypertensive medication and control rate in the Chinese hypertension population. The prevalence of hypertension will experience a substantial double increase, and the percentage of individuals recommended to take antihypertensive medications will have a small increase $(2.7 \%)$. In addition, the control rate of hypertension will decrease sharply from 46.7 to $11.2 \%$ among adults taking antihypertensive medications. It is important to determine how to address the 2017 ACC/AHA hypertension guideline? We should pay more attention to the positive impact of the 2017 ACC/AHA guideline and perform some cost-effectiveness analyses regarding the implementation of the guideline. Regardless, we should positively consider the control and management of hypertension, 
based on the real policies of China to further reduce the burden of CVD in China.

\section{Abbreviations}

ACC/AHA: American College of Cardiology / American Heart Association; CHNS: China health and nutrition survey; BP: Blood pressure; Cl: Confidence interval; JNC7: Seventh report of the joint National Committee: NHANES: National Health and nutrition examination survey; SBP: Systolic blood pressure; DBP: Diastolic blood pressure; CAPM: Chinese academy of preventive medicine; CVD: Cardiovascular disease; SD: Standard deviation; IQR: Interquartile range

\section{Acknowledgements}

Not applicable.

\section{Authors' contributions}

YJ, ZS, YX, JZ, ZL, XG, YD analyzed the data. YJ wrote the paper. YS, LZ designed the analysis and revised the paper, All authors had reviewed and agreed on the contents of this paper.

\section{Funding}

This research was partly supported by funds from National Nature Science Foundation of China (No. 81773510), Nature Science Foundation of Liaoning Province (No. 20170541048) and National Key R\&D Program of China (No.2018YFC1311600). The acquisition and analysis of data were supported by funds of National Nature Science Foundation of China and Nature Science Foundation of Liaoning Province. The revision of the written English were supported by funds of National Key R\&D Program of China.

\section{Availability of data and materials}

The datasets generated and/or analyzed during the current study are available in the China Health Nutrition Survey repository. Web link to datasets: https://www.cpc.unc.edu/projects/china.

\section{Ethics approval and consent to participate}

This study complies with the Declaration of Helsinki, and the Shengjing Hospital of China Medical University Research Ethics Committee approved the research protocol.

\section{Consent for publication}

Not applicable.

\section{Competing interests}

The authors declare that they have no competing interests.

\section{Author details}

${ }^{1}$ Department of Cardiology, Shengjing Hospital of China Medical University, 36 Sanhao Street, Heping District, Shenyang 110004, People's Republic of China. ${ }^{2}$ Department of Clinical Epidemiology, Department of Library, Shengjing Hospital of China Medical University, 36 Sanhao Street, Heping District, Shenyang 110004, People's Republic of China. ${ }^{3}$ Department of Cardiology, the First Affiliated Hospital of China Medical University, Shenyang 110001, People's Republic of China.

Received: 12 August 2019 Accepted: 12 May 2020

Published online: 19 May 2020

\section{References}

1. Whelton PK, Carey RM, Aronow WS, et al. 2017 ACC/AHA/AAPA/ABC/ACPM/ AGS/APhA/ASH/ASPC/NMA/PCNA guideline for the prevention, detection, evaluation and management of high blood pressure in adult. J Am Coll Cardiol. 2018;71(19):e127-248.

2. Chobanian AV, Bakris GL, Black HR, et al. The seventh report of the joint National Committee on prevention, detection, evaluation, and treatment of high blood pressure: the JNC7 report. JAMA. 2003;289(19):2560-72.

3. Muntner P, Carey RM, Gidding S, et al. Potential U.S. population impact of the 2017 American College of Cardiology/American Heart Association high blood pressure guideline. Circulation. 2017;137(2):109-18.

4. $\mathrm{Xi} \mathrm{B}$, Liang $Y$, Mi J. Hypertension trends in Chinese children in the national surveys, 1993 to 2009. Int J Cardiol. 2013;165(3):577-9.
5. Lu J, Lu Y, Wang X, et al. Prevalence, awareness, treatment, and control of hypertension in China: data from 1.7 million adults in a population-based screening study (China PEACE million persons project). Lancet. 2017; 390(10112):2549-58

6. Sun $Z$, Zheng $L$, Wei $Y$, et al. The prevalence of prehypertension and hypertension among rural adults in Liaoning province of China. Clin Cardiol. 2007;30(4):183-7.

7. Li Z, Guo Z, Zheng L, et al. Grim status of hypertension in rural China: results from Northeast China rural cardiovascular health study 2013. J Am Soc Hypertens. 2015;9(5):358-64.

8. Popkin BM, Du S, Zhai F, et al. Cohort profile: the China health and nutrition survey--monitoring and understanding socio-economic and health change in China, 1989-2011. Int J Epidemiol. 2010;39(6):1435-40.

9. CHNS China health and nutrion survey. Available from: http://www.cpc.unc. edu/projects/china/about/proj_desc/survey [cited 2017 November 17, 2017].

10. CHNS China health and nutrition survey. Available from: http://www. cpc.unc.edu/projects/china/data/datasets/biomarker-data [cited 2017 November 17, 2017].

11. Yan S, Li J, Li S, et al. The expanding burden of cardiometabolic risk in China: the China health and nutrition survey. Obes Rev. 2012;13(9):810-21.

12. Shen $L, M a H$, Xiang MX, et al. Meta-analysis of cohort studies of baseline prehypertension and risk of coronary heart disease. Am J Cardiol. 2013; 112(2):266-71.

13. Guo $X$, Zhang $X$, Zheng $L$, et al. Prehypertension is not associated with allcause mortality: a systematic review and meta-analysis of prospective studies. PLoS One. 2013;8(4):e61796.

14. Zheng L, Li J, Sun Z, et al. Relationship of blood pressure with mortality and cardiovascular events among hypertensive patients aged $\geq 60$ years in rural areas of China: a strobe-compliant study. Medicine (Baltimore). 2015;94(39):e1551.

15. Wright JT Jr, Williamson JD, Whelton PK, et al. A randomized trial of intensive versus standard blood-pressure control. N Engl J Med. 2015; 373(22):2103-016.

16. Qi Y, Han X, Zhao D, et al. Long-term cardiovascular risk associated with stage 1 hypertension defined by the 2017ACC/AHA hypertension guideline. J Am Coll Cardiol. 2018;72(11):1201-10.

17. Muntner P, Whelton PK. Using predicted cardiovascular disease risk in conjunction with blood pressure to guide anti-hypertensive medication treatment. J Am Coll Cardiol. 2017;69(19):2446-56.

18. Sundstrom J, Arima H, Woodward M, et al. Blood pressure-lowering treatment based on cardiovascular risk: a meta-analysis of individual patient data. Lancet. 2014;384(9943):591-8.

\section{Publisher's Note}

Springer Nature remains neutral with regard to jurisdictional claims in published maps and institutional affiliations.

\section{Ready to submit your research? Choose BMC and benefit from:}

- fast, convenient online submission

- thorough peer review by experienced researchers in your field

- rapid publication on acceptance

- support for research data, including large and complex data types

- gold Open Access which fosters wider collaboration and increased citations

- maximum visibility for your research: over $100 \mathrm{M}$ website views per year

At $\mathrm{BMC}$, research is always in progress.

Learn more biomedcentral.com/submission 